\title{
Integração de Tecnologias Digitais à Linguagem Oral e Escrita: um estudo de caso no Ensino Fundamental I
}

\author{
Rhayanne Y. Nakano ${ }^{1}$, Sabrina A. Rosa ${ }^{1}$, Selma Santos Rosa ${ }^{1}$, Rodrigo C. T. de \\ Souza $^{1}$, Valdir Rosa ${ }^{1}$ \\ ${ }^{1}$ Câmpus Avançado de Jandaia do Sul - Universidade Federal do Paraná (UFPR) \\ $\{$ rhayanne.nakano, selmasantos, valdirrosa, thom\} @ufpr.br
}

\begin{abstract}
Based on a case study consisting of a pedagogical intervention with 49 children the 5th year of elementary school I, the integration of Digital Technologies into teaching and learning of the Oral and Written Language (OWL) theme was analyzed. In the digital repositories, software product, applications and others were selected and, from this intervention, it was found that the integration of these technologies into the OWL increases the interest and motivation the children, improves the comprehension the contents or themes addressed, makes them more lively and happy, encourages them to learn and to dialogue with colleagues, breaks with the vision of technology use only for entertainment, not for educational purposes.
\end{abstract}

Resumo. A partir de um estudo de caso constituído de uma intervenção pedagógica com 49 crianças do $5^{\circ}$ ano do Ensino Fundamental I, analisou-se a integração de Tecnologias Digitais ao ensino-aprendizagem da temática Linguagem Oral e Escrita (LOE). Nos repositórios digitais, selecionaram-se produto de software, aplicativos e outros e, a partir dessa intervenção, se constatou que a integração dessas tecnologias à LOE aumenta o interesse e a motivação das crianças, melhora a compreenssão dos conteúdos ou temas abordados, as deixa mais animadas e felizes, as estimula para a aprendizagem e para o diálogo com os colegas, rompe com a visão do uso da tecnologia somente para o entretenimento, e não para fins educacionais.

\section{Introdução}

Por meio do estudo apresentado neste artigo, buscou-se contribuir com pesquisas relacionadas à integração de Tecnologias Digitais ao ensino e à aprendizagem da temática Linguagem Oral e Escrita (LOE), integrante do Ensino Fundamental I. Tal tema é, essencialmente, um dos principais objetivos desse nível de ensino e corresponde a um conjunto de habilidades que devem ocorrer de forma progressiva. São diversas as Tecnologias Digitais que podem ser utilizadas para contribuir com a aprendizagem, de forma positiva, da língua materna, desde simples blogs a aplicativos e jogos educacionais. Tem-se constatado que, nessa temática, a integração dessas tecnologias melhora a motivação e o desempenho das crianças, promove maior engajamento, conduz à aprendizagem grupal, permite desenvolver o pensamento critico e possibilita a reflexão, a colaboração e a interação [Nakano 2017; Camacho 2015; Weckelmann 2012; Caiado 2013]. 
VII Congresso Brasileiro de Informática na Educação (CBIE 2018)

Anais do XXIV Workshop de Informática na Escola (WIE 2018)

Estudos atuais revelam a grande dificuldade que as crianças possuem em relação à escrita, principalmente no que diz respeito à ortografia. Weckelmann (2012) costatou, em sua pesquisa, que existem diferenças em relação aos resultados das atividades realizadas no computador, pois possibilitaram elevar os níveis de motivação das crianças e a sua concentração, se comparados aos resultados das atividades realizadas de forma manuscrita. Essa constatação da autora pode consistir em um alerta aos docentes no sentido de estarem cada vez mais disponíveis para o uso de modo assíduo das Tecnologias Digitais [Fernandes 2014]. Segundo Costa et al. (2012, p. 31), "as Tecnologias Digitais são uma ferramenta (cognitiva) do aluno, porque o ajudam, sobretudo, a pensar e a resolver problemas, mas também a criar e a expressar-se ou a interagir e colaborar com os outros". Esse autor, assim como Monteiro (2017), defende que a utilização de Tecnologias Digitais traz um aprender poderoso (aprender-produção) e coloca em oposição a um uso escasso (aprender-reprodução), em que as tecnologias não trazem a imagem de um substituto do docente, mas, sim, de um auxiliar para novos conhecimentos. Isso propicia que o aluno progrida em suas capacidades de analisar, avaliar, refletir e decidir, entre muitos outros aspectos relacionados aos problemas encarados em seu cotidiano.

Santos e Barros (2008, p. 9) afirmam que "[...] o computador aguça a curiosidade do educando, libera sua criatividade, amplia a comunicação e torna $o$ processo ensino-aprendizagem mais ativo, autodirigido, carregado de significado". Essas autoras evidenciaram, em seu estudo, que o uso da informática e de suas tecnologias está previsto para o desenvolvimento de projetos educacionais que sejam capazes de estimular a interdisciplinaridade de forma lúdica e criativa por meio da internet e de softwares educacionais. Ressaltam, assim, a importância desses tipos de projetos, principalmente em escolas de período integral. Não obstante, identificaram também, limitações na sustentabilidade de uma cultura digital nas escolas devido a fatores diversos, tais como: a desatualização de algumas aplicações da Web 2.0, as licenças de uso, a falta de infraestrutura tecnológica, de logística e apoio técnico e de fluência tecnológica e pedagógica dos docentes para integrar tecnologias em suas práticas pedagógicas cotidianas.

Com vista a dar um contributo a pesquisas afins, neste artigo, apresenta-se um estudo que visou analisar a integração de Tecnologias Digitais ao ensino e à aprendizagem da temática LOE no $5^{\circ}$ ano do Ensino Fundamental I. Para isso, realizouse um estudo de caso em uma entidade beneficente que desenvolve atividades pedagógicas com crianças desse nível de ensino. Este estudo igualmente objetivou identificar Tecnologias Digitais com potenciais para contribuir com a aprendizagem da temática LOE e organizar espaços educacionais (sala de aula) para favorecer esta integração.

\section{Procedimentos Metodológicos}

O estudo de caso constituiu-se da modalidade de Investigação Colaborativa [Boavida e Ponte, 2002], realizada em um Centro Assistencial Público - Lar São Francisco de Assis (LSFA) - localizado em uma cidade do interior do Paraná, Brasil, o qual desenvolve atividades pedagógicas aliadas a outras de cunho social. Desde o seu início, em 1977, o LSFA oferece apoio a crianças de 6 a 12 anos que se encontram em estado de vulnerabilidade social [LSFA 2014]. Atualmente, atende por ano aproximadamente 200 
VII Congresso Brasileiro de Informática na Educação (CBIE 2018)

Anais do XXIV Workshop de Informática na Escola (WIE 2018)

crianças em regime de contraturno escolar, desenvolvendo diversos projetos educacionais e sociais.

O estudo de caso ocorreu no período de 23 de março a 13 de novembro de 2017 , totalizando, aproximadamente, 378 horas de intervenção. Dele participaram 49 crianças do $5^{\circ}$ ano do Ensino Fundamental I. A coleta de dados, por sua vez, se constituiu de 3 fases da pesquisa empírica: (a) Planejamento das aulas, momento no qual se procedeu à identificação, análise e seleção dos conteúdos curriculares e das tecnologias de apoio (software e hardware), como também à definição do espaço educacional; (b) Desenvolvimento das aulas, com base nas definições da fase (a). Nessa fase, se elaboraram registros do resultado da aprendizagem das crianças, por meio de suas anotações durante as aulas e da observação direta de suas ações durante os momentos da intervenção; e (c) avaliação e revisão dos elementos constituídos na fase (a) e (b) e análise dos dados obtidos.

Quanto às categorias de análise, se definiram a priori, tendo em vista as proposições da pesquisa. São elas: organização dos espaços educacionais e Tecnologais Digitais no LSFA; Competências instrumentais das crianças do $5^{\circ}$ ano do LSFA; e Integração das Tecnologias Digitais à LOE no LSFA. A análise dos resultados fundamentou-se em pesquisas afins.

Salientamos que esta pesquisa encontra-se aprovada pelo comitê de ética da Universidade Federal do Paraná com autorização para a divulgação de imagens e dos dados coletados.

\section{Resultados e Discussão}

Nesta seção, apresentamos os resultados obtidos por meio do estudo de caso. A discussão e análise dos resultados estão organizadas nas categorias definidas a priori, citadas anteriormente.

\subsection{Organização dos espaços educacionais e Tecnologias Digitais no LSFA}

Nesta categoria, teve-se a proposição de analisar como os espaços físicos de uma sala de aula equipada com Tecnologias Digitais podem ser organizados para fins didáticopedagógicos. Até 2015, as salas de aula do LSFA eram todas organizadas no formato tradicional, com as carteiras e as cadeiras enfileiradas e organizadas de modo que o aluno ficasse de frente para o quadro-negro. Esse tipo de organização pode prejudicar a interação entre as crianças e entre as crianças e o(a) professor(a). Igualmente, dificulta na maioria dos casos o desenvolvimento criativo, cooperativo, colaborativo e crítico do aluno. $\mathrm{O}$ (a) professor(a) é a primeira fonte de informação, é aquele que dissemina o conhecimento. Sendo assim, as crianças são passivas, apenas escutam e fazem o que lhes é pedido. As avaliações são desconectadas do aprendizado e, muitas vezes, não possuem quaisquer semelhanças com outras atividades realizadas em sala [Science, 2014].

Em 2016, por meio de um projeto de extensão universitária, levou-se ao LSFA a proposta de uma mudança cultural em suas questões didático-pedagógicas por meio da utilização da estratégia Hands-on-Tec [Santos Rosa, Rosa e Sales 2014], apoiada por Tecnologias Digitais móveis. Os autores dessa estratégia destacam alguns dos desafios encontrados nos cotidianos escolares para a integração de Tecnologias Digitais ao 
VII Congresso Brasileiro de Informática na Educação (CBIE 2018)

Anais do XXIV Workshop de Informática na Escola (WIE 2018)

currículo e para a estruturação de estratégias pedagógicas que culminem e sustentem essas tecnologias no contexto escolar. Tais desafios, segundo os autores, possui um histórico com dificuldades e, ao mesmo tempo, repleto de tentativas dos profissionais que intensificam seus esforços para o seu uso educacional. Os resultados das pesquisas utilizando a Hands-on-Tec culminaram na necessidade de estabelecer novas metodologias de ensino fundamentadas na aprendizagem significativa, bem como de uma reorganização do espaço educacional, ou seja, da sala de aula.

Após a implementação da Hands-on-Tec no LSFA, abriram-se novas possibilidades de se integrar as Tecnologias Digitais às atividades pedagógicas, fato que viabilizou a presente pesquisa e tem oportunizado o uso desse ambiente por todas as professoras do LSFA durante suas aulas. Na Figura 1, apresenta-se a sala de aula reorganizada a partir da implantação da Hands-on-Tec, com recursos digitais e, na Figura 2, crianças durante uma atividade utilizando tablets e acessando objetos de aprendizagem por meio de $Q R C o d e$.

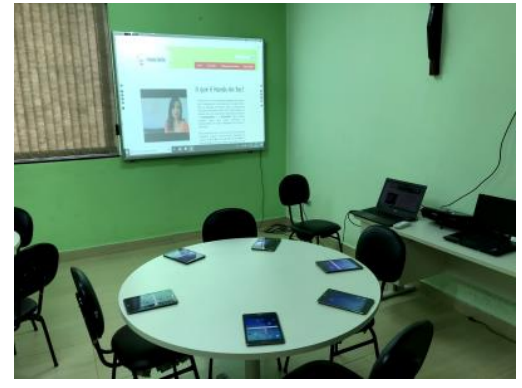

Figura 1. Sala de aula Hands-on-Tec

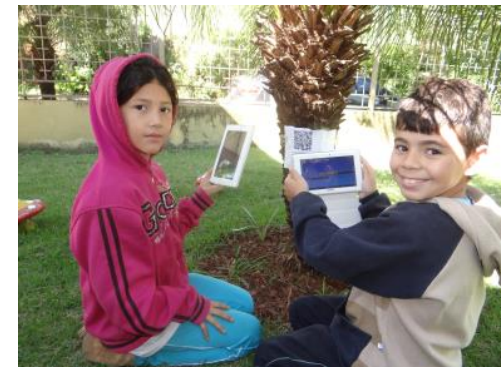

Figura 2. Crianças em atividade

Conforme mostrado na Figura 1, o ambiente possui boa ventilação e luminosidade, é limpo e amplo, facilitando assim seu uso e fluxo entre as mesas, além de permitir mobilidade e trabalho cooperativo. Ressalta-se que, no campo educacional, adaptar-se às novas gerações faz parte do processo de inovação e que, atualmente há uma grande diversidade de alterações que podem ser adotadas para melhorar cada vez mais a educação.

Durante as intervenções, duas professoras acompanharam as aulas. Durante as reuniões com elas constatou-se que, antes da implementação da Hands-on-Tec, elas trabalhavam de forma similar às escolas públicas regulares da região, ou seja, da forma tradicional, sem Tecnologias Digitais. Após a introdução do projeto Hands-on-Tec, mudaram suas estratégias e passaram a utilizar cada vez mais as Tecnologias Digitais disponíveis. Nas aulas, a utilização de textos interativos e audiobooks por exemplo são recursos que chamam a atenção das crianças, podendo estimular tanto a leitura quanto a escrita em diferentes momentos do processo de ensino e aprendizagem.

A sala de aula Hands-on-Tec do LSFA possui boas condições de uso para fins pedagógicos: 02 caixas de som, 01 datashow, 01 lousa digital, um desktop, 05 ultrabooks, 15 tablets e acesso à internet banda larga suficiente para reproduzir recursos multimídia (vídeos, imagens, jogos, animações etc.) simultaneamente de pelo menos 60 crianças. 
VII Congresso Brasileiro de Informática na Educação (CBIE 2018)

Anais do XXIV Workshop de Informática na Escola (WIE 2018)

\subsection{Competências instrumentais das crianças do $5^{\circ}$ ano do LSFA}

Esta categoria possibilitou identificar o conhecimento que uma pessoa possui sobre o uso instrumental (saber ligar, manusear ferramentas etc.) de tecnologias computacionais (computador, tablet e celular) e seus derivados (datashow, lousa digital, câmera digital). No âmbito da presente pesquisa, identificaram-se as competências instrumentais das crianças participantes. Para isso, questionou-se: qual o nível de conhecimento das crianças sobre: como ligar e desligar tecnologias computacionais e seus derivados, salvar arquivos, realizar buscas na internet?

O resultado se deu a partir de diálogos e da constante observação durante as aulas da intervenção. Cerca de $90 \%$ das crianças, em ambos os períodos, afirmaram que não sabiam usar Tecnologias Digitais, o que foi confirmado durante a utilização desses recursos. Algumas alegaram que não sabiam utilizar pelo fato de não possuírem esses recursos em suas residências, podendo, portanto, ser considerados leigos no assunto. Entretanto, em determinadas aulas, alguns entravam em contradição, quando encontravam algum problema para manusear o equipamento, afirmando o seguinte: "Eu não sei como faz isso nesse computador, no meu é diferente". Essa afirmação permite levanter dois pontos para reflexão: ou o aluno omitiu a informação de que possui tal equipamento em casa ou, de certa forma ficou constrangido por não conseguir manuseálo.

Ainda em relação à afirmação anterior, constatou-se que não ocorreu apenas uma vez ou apenas com um aluno, mas sim, várias vezes com diversas outras crianças, o que sugere que não possuem o equipamento, dificultando um pouco o seu manuseio no nível instrumental.

\subsection{Integração das Tecnologias Digitais à LOE no LSFA}

Para a definição dos conteúdos, realizaram-se reuniões com duas professoras que trabalham com LOE, para que fosse possível confirmar os conteúdos que seriam desenvolvidos durante a intervenção com as crianças. Como resultado, definiu-se a partir de uma consulta à Base Nacional Comum Curricular (BNCC), uma lista de conteúdos a serem trabalhados nas aulas do período da intervenção, compreendido entre março e novembro de 2017. A partir desse levantamento, passou-se para a próxima etapa, que foi selecionar Tecnologias Digitais (softwares, aplicativos e outros) com recursos aos conteúdos dos eixos identificados na BNCC: escrita $(n=93)$, leitura $(n=27)$, oralidade $(n=2)$ e alfabetização inicial $(n=11)$.

O eixo da escrita foi o primeiro a ser abordado, ao qual se deu maior ênfase na pesquisa, pois a disponibilidade de Tecnologias Digitais para trabalhá-lo foi maior em comparação aos outros eixos $(n=93)$. Foi claramente visível o grande interesse das crianças em iniciar as atividades propostas, por mais que se queixassem, afirmando que a Língua Portuguesa é a mais "chata" de todas. Entretanto, ficaram empolgados quando se disse que as aulas seriam realizadas com mediação digital. Esse fato corrobora a pesquisa de Caiado (2013) e a de Weckelmann (2012), que constataram melhorias na motivação das crianças ao utilizar Tecnologias Digitais. Contudo, constatou-se durante essas atividades a dificuldade que todas apresentavam, sem exceção, principalmente quanto à formação de palavras e à ortografia. 
VII Congresso Brasileiro de Informática na Educação (CBIE 2018)

Anais do XXIV Workshop de Informática na Escola (WIE 2018)

Quando questionadas sobre seus conhecimentos em relação à ortografia, as crianças afirmaram que possuíam grande conhecimento sobre o tema. Assim, ao proceder com as atividades, as crianças realizavam comentários dos mais variados, como, por exemplo, que o assunto seria muito fácil e, portanto, que o término das atividades ocorreria de forma muito rápida Também fizeram outros comentários: "Para que vou precisar disso?", "Isso não é importante!", "Eu acertei sim, o computador que tá errado!". Cerca de $70 \%$ das crianças não conseguiram entender a diferença entre palavras escritas com S e Z, por exemplo. Essas dificuldades preocuparam e apareceram de forma constante durante a pesquisa realizada por Fernandes (2014).

As inadequações ao padrão formal, não ocorreram apenas na escrita, mas também nos momentos de diálogos e durante a leitura de atividades. Entre as inadequações mais recorrentes observados nas atividades, destacam-se: "eu ponhei", "menas", "a fulana ponhô", "nóis foi", "a gente fomos" e, assim por diante. Prosseguindo com os conteúdos, as aulas se tornaram um pouco conturbadas, pelo fato de algumas crianças não conseguirem identificar a diferença entre substantivos, adjetivos e verbos. Para elas, tudo era igual. Esses três itens, para mais da metade das crianças, foram muito difíceis e, devido a isso, ocorreu de forma inicial, uma diminuição no interesse delas. Ao serem questionadas sobre o motivo do descontentamento, trouxeram à tona novos comentários, como: "não, minha escola não ensina isso", "nunca estudei isso", "a professora não ensinou", "é muito chato", "a professora só manda copiar um monte de texto".

Ao presenciar os comentários mencionados e observar o semblante de desânimo das crianças, explicou-se a elas como seriam trabalhados esses três itens. Muitas disseram que pensaram que seriam obrigadas a copiar uma enorme quantidade de textos. Algumas delas disseram que não aguentavam mais copiar textos, porque assim faziam nas escolas regulares. Assim, ao introduzir tais atividades derivadas de sites que possuíam jogos, quizes etc., logo se notou, quase instantaneamente uma mudança no comportamento de algumas dessas crianças. O interesse em realizar as atividades cresceu, assim como a motivação em terminar uma para poder passar para a próxima. Debates entre os colegas começaram a ser gerados de forma constante, sendo que todos tentavam ajudar uns aos outros, características consideradas positivas que também foram apresentadas por Camacho (2015), Fernandes (2014) e Monteiro (2017).

A compreensão entre os adjetivos e substantivos foi o mais complicado de se lidar, pois, em determinadas atividades, algumas crianças ainda confundiam ambos os significados. Entretanto, grande parte dessas atividades que pediam a utilização de adjetivos ou substantivos possuíam explicações escritas de forma simples e de fácil compreensão, para auxiliá-los. Assim, novamente, foi possível perceber que aquelas crianças que estavam constantemente errando em algum momento, o faziam pelo fato de não terem lido a explicação da tela inicial. Mas, em compensação, diferenciar os verbos foi algo que ocorreu com maior facilidade.

Em seguida, fez-se uma abordagem sobre sinônimos e antônimos em um tempo mais curto, se comparados aos temas anteriores, pelo fato de não ter sido possível encontrar softwares relacionadas ao tema. Porém, foi suficiente para que as crianças pudessem, ao menos, compreender o básico. A dificuldade que elas possuíam nos conteúdos anteriores se intensificou nessas aulas. 
VII Congresso Brasileiro de Informática na Educação (CBIE 2018)

Anais do XXIV Workshop de Informática na Escola (WIE 2018)

Ao iniciar a aula sobre sinônimos e antônimos, o primeiro comentário foi: "Eu não sei o que significa sinônimo/antônimo". Supostamente, nenhuma das crianças havia sequer ouvido falar sobre tais palavras até o presente momento ou não as internalizaram. Contudo, ao dar seguimento às atividades, aos poucos, começaram a lembrar vagamente o que significavam ambas as palavras, e o que antes era algo difícil, se tornou divertido. Observando seus semblantes, percebia-se que, ao mesmo tempo em que realizavam as atividades, estavam focadas e animadas com o uso das Tecnologias Digitais. Em dados momentos, se exaltavam, ao terminar uma atividade primeiro que um outro colega. Ao final dessas aulas, houve comentários bem diferentes e até um pouco inesperados em comparação à primeira aula sobre o assunto, como, por exemplo: "agora eu aprendi", "é muito fácil", "na escola onde estudo isso é muito difícil, aqui não" (ao se referirem ao uso das tecnologias).

Uma vez estudado o assunto supracitado, seguiu-se para a acentuação. Algo que preocupou logo no início das atividades foi que diversas crianças não sabiam nomear os acentos. Porém, sabiam quais eram os adequados para as palavras solicitadas. Ao utilizar os ultrabooks, pôde-se perceber de forma mais clara essa situação, pois possuíam um formato diferente dos padrões de teclado, já que não haviam impressas, nas teclas, os acentos e algumas letras, como o "ç", ou seja, ficavam escondidas em outras teclas. Além disso, em determinadas atividades, não eram aceitas as acentuações diretas nos campos solicitados, sendo necessário fazer uso das demais habilidades básicas de informática e coordenação motora, às quais as crianças não estavam habituadas. Quando se fazia necessário digitar alguma palavra que precisasse de algum desses itens (acentos ou letras especiais), simplesmente perguntavam: "Como que faz aquele acento com risco?", "Cadê o acento que é tipo uma minhoca?", "Nesse computador não tem aquele chapeuzinho do vovô?". Em alguns casos, não sabiam expressar com palavras o acento desejado. Então, simplesmente demonstravam visualmente com a mão em movimento o formato do acento.

Após a acentuação, vieram os sinais de pontuação, sendo que a maioria das crianças sabia o nome de cada um. Porém, ocorreram alguns cenários como, por exemplo, trocar o nome da pontuação pelo da acentuação. Para ambos os conteúdos, houve uma escassez de sofwares, o que tornou curta a duração da temática.

As produções escritas ajudaram a perceber a grande dificuldade que as crianças possuíam por não terem o costume de utilizar a letra cursiva, mas letras de forma. Ao serem questionadas do porquê da não utilização da letra cursiva, as crianças disseram que era mais fácil escrever assim. Afirmaram, porém, que sabiam todo o alfabeto maiúsculo e minúsculo na forma cursiva. Não obstante, pôde-se perceber, durante as atividades, que elas não sabiam. Além disso, houve um certo empecilho: cerca de $90 \%$ da turma possuía aversão ao desenvolvimento de textos ou à realização das anotações de aulas. Para a criação de novos textos em específico, apresentaram grande dificuldade em iniciá-los.

Já as atividades de produção oral das crianças foram realizadas de forma intercalada com a produção escrita e os demais tópicos anteriores. Devido ao fato de elas possuírem "gosto" pela leitura, o trabalho docente foi facilitado. Porém, apesar disso, as crianças alegaram que não as realizavam com frequência fora do ambiente escolar. Talvez devido a esse fator, mais da metade das crianças demonstrou grande 
VII Congresso Brasileiro de Informática na Educação (CBIE 2018)

Anais do XXIV Workshop de Informática na Escola (WIE 2018)

dificuldade em realizar a leitura de textos simples. Além disso, nem todas se sentiam seguras em realizar tais atividades, dada a necessidade de se exporem um pouco mais. Então, para isso, decidiu-se trabalhar caso a caso. Para que essas crianças se sentissem seguras, o apoio da docente e dos demais colegas foi essencial, o que fez com que, aos poucos, se acostumassem a ler, deixando o medo cada vez mais de lado e, inclusive, tomando gosto pela leitura.

A expressão de felicidade das crianças, durante as aulas, tornou-se gratificante, pois foi possível perceber o quanto gostavam de aprender daquele jeito (com tecnologias) e o quanto isso as estimulou para aprender e dialogar, características positivas também apresentadas nas pesquisas de Camacho (2015), Fernandes (2014) e Weckelmann (2012).

Nas intervenções realizadas no estudo de caso, pôde-se perceber que as crianças, de fato, possuíam muito interesse em ter aulas mediadas por Tecnologias Digitais, pois é algo que chama muito a sua atenção, como afirma Costa (2012) e Santos e Barros (2008). Por determinados temas, algumas crianças não pareciam ter interesse, e outras queriam apenas jogar jogos distintos, pois, segundo suas argumentações, seus responsáveis permitiam que jogassem qualquer tipo de jogo quando bem entendessem em suas casas, por meio de smartphones e/ou computadores, equipamentos dos próprios responsáveis. Outros não possuíam tais equipamentos em casa, porém, possuíam a visão de que as Tecnologias Digitais foram criadas apenas para jogar jogos e nada mais, conforme alguns colegas afirmavam. Isso gerou, nas crianças, uma visão um pouco deturpada sobre o que se pode fazer, de fato, com as Tecnologias Digitais, as quais, no caso, não não usadas apenas para jogar um "joguinho" qualquer. Esse fato trouxe à tona algumas dificuldades durante as aulas no período da manhã, pois levou certo tempo para fazer com que as crianças compreendessem que é possível aprender conteúdos da LOE por meio de atividades específicas com o auxílio da internet e tablets ou ultrabooks, por exemplo. Assim, em determinados momentos, a falta de vontade de algumas crianças foi preocupante, pois isso ocorreu em atividades nas quais elas demonstravam dificuldades e, mesmo assim, não pareciam se importar com isso.

Questionamentos da professora direcionados às crianças e não ao conteúdo em si, eram realizados com certa frequência. Começaram a surgir perguntas feitas pelas professoras, como "a aula está chata?"; "você não acha importante aprender isso para o seu futuro?", entre outras, e respostas das crianças um pouco fora do convencional, como "meu pai não terminou a escola, então eu também não preciso"; "queria que no futuro não existisse mais escola"; "a escola é chata, as aulas são chatas, as professoras são chatas"; "quando eu crescer vou ser caminhoneiro, então não preciso ir para a escola"; "a gente só copia porque senão a professora grita com a gente". Compreendeuse então que, a falta de interesse de alguns crianças poderia ser decorrente do que se passava em suas escolas regulares. Considera-se que tais comentários não deveriam ocorrer de forma tão prematura e convicta. Afinal, essas crianças estão apenas nos anos iniciais da vida escolar e já demonstram uma falta de interesse tão grande.

Após esse período de aceitação, as crianças se adaptaram mais facilmente às atividades propostas em sala. Discutiam muito entre si e mostravam muito interesse durante as aulas. Havia entre as crianças, algumas com grandes dificuldades de comunicação com a professora ou com os demais colegas, algo que preocupou nas 
VII Congresso Brasileiro de Informática na Educação (CBIE 2018)

Anais do XXIV Workshop de Informática na Escola (WIE 2018)

primeiras semanas. Porém, após o primeiro mês, passaram a dialogar e a interagir e, inclusive, davam ideias para a professora para fazer algo a mais durante a finalização de alguma atividade do dia. Fato inesperado e causador de uma grande evolução em um curto espaço de tempo, porém, que já havia sido constatado por Costa et al. (2012) e Weckelmann (2012) e Camacho (2015) em suas pesquisas.

No decorrer das aulas, observou-se que as crianças ficavam de forma mais descontraída, às vezes até demais. Afinal, podiam dialogar com os colegas e com a professora sempre que fosse necessário. No entanto, durante as atividades escritas, como produção textual, no caso da redação, ou até mesmo repassar a limpo algum texto ou atividade realizada online, notou-se que elas possuíam muita dificuldade na escrita e também na compreensão do texto e do enunciado da atividade. As crianças pareciam não possuir o costume de ler os enunciados das atividades, as instruções nem as dicas. Muitas esperavam que alguém simplesmente lhes desse a resposta. Dessa forma, acabavam tendo sérias dificuldades ao tentar fazer as atividades propostas, pois, afinal, em praticamente todas elas, era necessário fazer uso da interpretação.

Durante todas as aulas, houve mudanças considerando o curto período de acompanhamento. $\mathrm{O}$ que mais chamou a atenção foi o aumento do interesse por determinados conteúdos da LOE pelos quais demonstraram, inicialmente, resistência e pelos quais, no final, acabaram se interessando mais do que o esperado.

As aulas foram ministradas dentro de uma sala específica (a Hands-on-Tec), como já mencionado. $\mathrm{O}$ uso de Tecnologias Digitais foi um diferencial que colaborou significantemente para o desenvolvimento da presente pesquisa, diferente do que constatou Caiado (2013). Segundo esse autor, em sua pesquisa, uma das professoras observadas relatou ter tido problemas com o laboratório de informática devido à necessidade da presença de um técnico na área, a problemas com a manutenção e, aparentemente, à consideração de que o espaço era irrelevante. Isso não ocorreu durante a pesquisa ora apresentada, pois, os fatos de não ter a necessidade de depender de alguém para liberar a utilização do espaço e de deixar em segundo plano a manutenção da sala foram pontos positivos que facilitaram o estudo de caso. Como ocorre com qualquer equipamento tecnológico, existiu a necessidade de realizar manutenções. Contudo, foram realizadas em um dia específico da semana, fora do horário de aula, para que não houvesse interferências.

\section{Considerações Finais}

A alfabetização é de extrema importância para as crianças e consite em um momento de descoberta. Nessa direção, considera-se que integrar as Tecnologias Digitais às aulas não só pode, como deve ajudar a tornar o ambiente mais interativo, lúdico e também atrativo. $\mathrm{O}$ emprego dessas tecnologias nas escolas, almejando o ensino e a aprendizagem em LOE, mostra-se uma necessidade cada vez maior, uma vez que a taxa de analfabetismo continua alta na rede pública de ensino. Vale ressaltar que as políticas e a falta de recursos tecnológicos apropriados nas escolas públicas ainda são barreiras que impedem a devida integração.

Ao longo desta pesquisa, constatou-se que a integração dessas tecnologias à LOE aumenta o interesse e a motivação, melhora a compreensão dos conteúdos ou temas abordados, deixam as crianças mais animadas e felizes, as estimula para a aprendizagem 
VII Congresso Brasileiro de Informática na Educação (CBIE 2018)

Anais do XXIV Workshop de Informática na Escola (WIE 2018)

e para o diálogo com os colegas e rompe com a visão de uso da tecnologia somente para o entretenimento, e não para uso educacional. Outrossim, salienta-se que a necessidade de investimento colaborativo no desenvolvimento de softwares ou aplicativos para cobrir as demandas dos eixos temáticos tratados neste estudo constituem um foco para $o$ futuro das pesquisas e para o desenvolvimento tecnológico com vistas à integração de Tecnologias Digitais à LOE no Ensino Fundamental.

\section{Referências}

Boavida, A. M., Ponte, J. P. (2002). Investigação colaborativa: potencialidades e problemas. In: GTI (Org). Reflectir e investigar sobre a prática profissional. Lisboa: APM, p. 43-55.

Caiado, R. V. R. e Morais, A. G. (2013). "Práticas de ensino de língua portuguesa com as TDIC”. Educação Temática Digital. v. 15, n. 3, p.578 - 594.

Camacho, R. B. (2015). "Relación entre tic y la adquisición de habilidades de lectoescritura em alumnos de primer grado de básica primaria”. Investigación \& Desarrollo, Barranquilla, v. 23, n. 2, p. 338-368. https://goo.gl/z9Grfi, Fevereiro.

Costa, F. A., Rodriguez, C., Cruz, E. e Fradão, S. (2012). "Repensar as TIC na educação: O professor como agente transformador". Carnaxide: SANTILLANA.

Fernandes, M. A. S. (2014). "O ensino e aprendizagem da escrita com recursos digitais: a aula de língua portuguesa no $5^{\circ}$ ano de escolaridade". Lisboa: UAB https://goo.gl/gPqY4n, Agosto.

LSFA. (2014). Centro Assistencial Lar São Francisco de Assis. Disponível em: $<$ http://lsfa.org.br/tag/jandaia-do-sul/>. Acesso em: 01 de mar de 2017.

Monteiro, M. T. M. M. M. S. (2017).“A utilização da WebSocial na disciplina de Português numa turma do $2^{\circ}$ Ciclo do Ensino Básico". Lisboa: UAB, https://goo.gl/1yKGr3.pdf, Agosto.

Nakano, R. Y. (2017). Integração de Tecnologias Digitais á Temática Linguagem Oral e Escrita no Ensino Fundamental I. Trabalho de Conclusão de Curso. Universidade Federal do Paraná.

Rosa, S. S., Rosa, V. e SALES, M. B. (2014). "Portal virtual Hands-on-Tec: recurso de autoria para professores da educação básica". Multimedia Journal of Research in Education, v. 1, p. 1-6.

Santos, G. Maria. C. e Barros, D. M. V. (2008). "Escola de tempo integral: a informática como princípio educativo". no 46/8. https://goo.gl/xyHQcx, Abril.

Science. (2014). Lectures aren't just boring, they're Ineffective, too, study finds. AAS: Washington. 12 mai. Disponível em: <https://goo.gl/ds9Ead $>$. Acesso em: 01 de set de 2017.

Weckelmann, V. F. (2012). "Indicadores de mudanças nas práticas pedagógicas com o uso do computador portátil em escolas do Brasil e de Portugal”. São Paulo: PUCSP. https://goo.gl/T7bAbU, Agosto. 